\title{
Mariolina Bongiovanni Bertini, «Gautier critique de Balzac»
}

\section{Marco Stupazzoni}

\section{Q OpenEdition \\ 1 Journals}

\section{Edizione digitale}

URL: https://journals.openedition.org/studifrancesi/37968

DOI: $10.4000 /$ studifrancesi.37968

ISSN: 2421-5856

\section{Editore}

Rosenberg \& Sellier

\section{Edizione cartacea}

Data di pubblicazione: 15 décembre 2004

Paginazione: 634

ISSN: 0039-2944

\section{Notizia bibliografica digitale}

Marco Stupazzoni, «Mariolina Bongiovanni Bertini, «Gautier critique de Balzac»», Studi Francesi [Online], 144 (XLVIII | III) | 2004, online dal 30 novembre 2015, consultato il 08 mai 2021. URL: http:// journals.openedition.org/studifrancesi/37968; DOI: https://doi.org/10.4000/studifrancesi.37968

Questo documento è stato generato automaticamente il 8 mai 2021.

\section{(c) $(1) \odot \odot$}

Studi Francesi è distribuita con Licenza Creative Commons Attribuzione - Non commerciale - Non opere derivate 4.0 Internazionale. 


\title{
Mariolina Bongiovanni Bertini, «Gautier critique de Balzac»
}

\author{
Marco Stupazzoni
}

\section{NOTIZIA}

MARIOLINA BONGIOVANNI BERTINI, «Gautier critique de Balzac», in «Cahiers de l'Association internationale des études françaises», mai 2003, n5 55, pp. 501-518.

1 A partire grosso modo dal 1856, si assiste, in Francia, ad una nuova e più equilibrata valutazione dell'opera di Balzac e della personalità umana e letteraria dello scrittore. Grazie soprattutto agli scritti che L. Gozlan, L. Surville (sorella di Balzac) e G. Sand dedicarono al romanziere, si afferma e si consolida progressivamente un'immagine dello scrittore lontana dalle caratterizzazioni stereotipate e caricaturali dominanti nei decenni precedenti: emerge così il ritratto di un Balzac «vivant et bien capable de conquérir par sa bonne foi et par son humour le public jusqu'alors séduit plutôt par ses récits et par sa personne» (p. 504). A questa nuova atmosfera di rinato fervore balzachiano, appartengono due studi di particolare rilievo: tra il febbraio e il maggio 1858, vedono, infatti, la luce i saggi di Taine e di Gautier su Honoré de Balzac, pubblicati rispettivamente nel «Journal des débats» (3 febbraio-3 marzo) e ne «L'Artiste» (21 marzo-21 maggio). Le puntuali e pregevoli riflessioni critiche condotte da Mariolina Bongiovanni Bertini sui due testi in oggetto consentono al lettore di valutare con chiarezza i momenti fondamentali della riflessione di Gautier e di Taine a proposito di Balzac e della sua opera. In entrambi gli autori, è convergente l'idea che sia l'immaginazione a costituire, in Balzac, «l'élément capital de son génie, le secret de sa force, de son originalité et de l'extraordinaire vitalité de son oeuvre» (p. 512), mentre assistiamo, osserva sempre l'A., a due visioni "parfaitement incompatibles de l'homme Balzac» (p. 516). Al Balzac 'artiste' di Gautier, che, non a caso, definisce l'autore della Comédie humaine come "l'écrivain le plus romantique qui ait jamais existé", Taine presenta l'immagine di uno scrittore 'mutilato' «de son goût du fantastique, de son humour et de son intuition des nuances les plus délicates de la psychologie féminine» 
(p. 517). Al rigore implacabile di Taine, Gautier oppone la fine curiosità del "flâneur" alla ricerca di infinite e nascoste "trouvailles" all'interno di un'opera, La Comédie humaine, dove «les moindres babioles» sono tesori «qui parlent à sa mémoire et à son imagination, qui suscitent son enthousiasme» (p. 518). 